\title{
Fuel consumption optimization of a multimachines microgrid by secant method combined with IPPD table
}

\author{
Firas Alkhalil*(1), Philippe Degobert*(1), Frédéric Colas*(1) and Benoit Robyns*(2), Member, IEEE \\ * Laboratoire d'Electrotechnique et d'Electronique de Puissance de Lille (L2EP). \\ (1) Arts et Métiers ParisTech, L2EP, Lille, France \\ Phone/Fax number: +33 (0)3-20-62-22-29/+33(0)3-20-62-27-50 \\ firas.alkhalil-8@etudiants.ensam.fr, philippe.degobert@ensam.eu , frederic.colas@ensam.eu \\ (2) Ecole des Hautes Etudes d'Ingénieurs, L2EP, Lille, France \\ Phone/Fax number: +33 (0)3-28-38-48-58/ +33 (0)3-28-38-48-04 \\ benoit.robyns@hei.fr
}

\begin{abstract}
The objective consists in optimizing the fuel consumption of a power station of small cogeneration multi machines while minimizing generated pollution. At first, a study carried out on the strategies of Economic Dispatch , was used to us to solve the unit commitment problem, whose main aim is to determine the optimal schedule of online generating units so as to meet the power demand at minimum operating cost under various system and operating constraints. This work was carried out by Secant method combined with Improved Pre-prepared Power Demand (IPPD) table which obtains the unit status information and then the optimal solution is achieved by Secant method at each power demand for 24 hours. The comparison of results of the proposed method with the results of classical method, by Matlab/Simulink, shows that the proposed approach provides qualitative solution.
\end{abstract}

\section{Keywords}

Gas micro turbine, unit commitment problem, Secant method, Economic Dispatch, IPPD table and Quadratic fuel cost function.

\section{Sympols and notations}

$F_{i}\left(P_{i}\right)$ Generator fuel cost of $\mathrm{i}^{\text {th }}$ generating unit

$\lambda_{i} \quad$ Incremental fuel cost of $\mathrm{i}^{\text {th }}$ generating unit

$p_{i} \quad$ Real power output of $\mathrm{i}^{\text {th }}$ generating unit

$P D$ Demand Power

$N_{g} \quad$ No. of generating units.

$P_{i, \min }$ Minimum real output power of $\mathrm{i}^{\text {th }}$ generating unit

$p_{i, \max }$ Maximum real output power of $\mathrm{i}^{\text {th }}$ generating unit

$T_{\text {oni }}$ is on time duration of $\mathrm{i}^{\text {th }}$ hour

$T_{M U_{i}}$ is minimum up time of the generating unit.

$T_{o f f} i$ is off time duration generating unit.

$T_{M D_{i}}$ is minimum down time for unit $\mathrm{i}^{\text {th }}$.

\section{Introduction [1], [2], [7]}

Unit commitment (UC) is the problem of selecting the generating units to be in service during a scheduling period and for how long. The overall problem can be divided into two sub problems namely unit commitment and economic dispatch. The committed units must meet the system load and reserve requirements at minimum operating cost, subject to a variety of constraints. The Economic Dispatch Problem (EDP) is to optimally allocate the load demand among the running units while satisfying the power balance equations and units operating limits. The solution of the (UCP) is really a complex optimization problem. It can be considered as two linked optimization problems, the first is a combinatorial problem and the second is a nonlinear programming problem. The unit commitment decision involves the determination of the generating units to be running during each hour of the planning horizon by considering system capacity requirement and the economic dispatch decision involves the allocation of the system demand and spinning reserve capacity among the operating units during each specific operation of power.

In this paper, we used a classical method to solve unit commitment problem. Beside, Secant method combined with IPPD table is proposed for solving UC problem. The proposed algorithm was implemented in MATLAB (6.5 Version). The paper is organized as follows:

In Section.2, Unit commitment problem formulation is introduced. Section.3 addresses the solution methodology for UC problem. Implementation of algorithm is given in Section.4. Application of the classical method to a central multimachine small co-generation mode can operate logged to the network or isolated is presented in section .5. The simulation and comparison results of power system with various generator units are presented in Section.6. Conclusions are finally given in the last section. 


\section{Unit Commitment Problem (UCP)}

The object of unit commitment is to decide which of the available generators should start-up and shut-down over a given time horizon so that the overall operating cost is minimised subject to demand and spinning reserve constraints $[2,13]$.

\section{A. Objective function:}

The objective function of UC problem is expressed as the sum of fuel cost, the start up and shut down cost of individual units for the given period subjected to various constraints. Mathematically it can be formulated as follows:

$$
F_{\min }=\sum_{t=1}^{n t} \sum_{i=1}^{n g} c_{i}\left(p_{i, t}\right) I_{i, t}+S U_{i, t}+S D_{i, t}
$$

The startup cost is considered as an exponential function of off time of a generating unit and the corresponding equation is:

$$
S U_{i, t}=S O_{i} \cdot\left\lfloor 1-D_{i} \cdot\left(e^{\left(-T_{o f f} / T_{\text {down }}\right)}\right)\right\rfloor
$$

Considering the fuel cost function as a quadratic function of real power generation fig, ED problem can be formulated as follows:

$$
c_{i}\left(p_{i, t}\right)=a_{i}+b_{i} P_{i, t}+c_{i} P_{i, t}^{2}
$$

\section{B. Constraints [2], [7]:}

Depending on the nature of the power system under study, The UCP has many constraints such as the power balance, spinning reserve and the other constraints including the thermal constraints, fuel constraints and security constraints.

1) Load balance constraint. The real power generated must be sufficient enough to meet the load demand and must satisfy the following equation:

$$
\sum_{i=1}^{N} P_{i, t} U_{i, t}=P D_{t}
$$

2) Limits of generating units. The output power of each generating unit must within its allowable minimum and maximum limits.

$$
P_{i, \min }<P_{i, t}<P_{i, \max }
$$

3) Spinning reserve constraints. Spinning reserve must be considered to meet abrupt load variations and unexpected generating unit outage. It is the total amount of power generation available from all units minus present load.

$$
\sum_{i=1}^{N} P_{i, \max } U_{i, t} \geq P D_{t}+R_{t}
$$

4) Thermal constraints. The temperature and pressure of the thermal units vary very gradually and the units must be synchronized before they are brought online. A time period of even 1 hour is considered as the minimum down time of the units. There are certain factors, which govern the thermal constraints like minimum up time, min down time and the crew constraints.

a) Minimum up time. If the units have already been shut down, then there is a minimum time before which they can be restated.

$$
T_{o n_{i}} \geq T_{M U_{i}}
$$

b) Minimum down time. If all the units are running already, then they cannot be shut down simultaneously.

$$
T_{o f f_{i}} \geq T_{M D_{i}}
$$

c) Must run units. Generally in a power system, some of the units are given a must run status in order to provide voltage support for the network.

\section{Solution Methodology of UCP}

\section{A. Formation IPPD table $[2,7]$ :}

The procedure to find IPPD table is as follows,

1) Selection of the Lambda values:

Find minimum and maximum lambda values for all generators at their maximum and minimum output power values.

$$
\begin{aligned}
& \lambda_{i, \min }=b_{i}+2 c_{i} p_{i, \text { min }} \\
& \lambda_{i, \max }=b_{i}+2 c_{i} p_{i, \max }
\end{aligned}
$$

2) Arrange all the lambda values in ascending order.

3) Find the output power values for all generators at all lambda values. The generator constraints are considered as follows,

$$
\text { if } \lambda_{i, t}<\lambda_{i, \min } \ldots . . \text { then } \quad P_{i, t}=0
$$

For must run generators:

$$
\text { if } \lambda_{i, t}<\lambda_{i, \min } \ldots . . \text { then } \quad P_{i, t}=P_{i, \min }
$$


4) Arrange lambda, powers, and sum powers at lambda in table is known as IPPD table. It gives the information about all predicted power demands and the information of committed units.

5) At specified power demand, the upper and lower rows of the IPPD able are selected such that the power demand at that hour lies within the IPPD limits. Each column represents the information about the status of the generating units. If any value of column is zero, then that corresponding generating units is off condition and the remaining units are in on condition. Therefore with help of the IPPD table, the information of status of unit's is determined. Whenever the information of committed units is known, then the economic dispatch is used to find the optimal solution.

B. Secant method for EDP[2-6][8]:

1) At each power demand over 24 hours, IPPD table gives the information of unit status. Now, the economic dispatch is used to find the optimal solution for all forecasted power demands over 24 hours. In this paper, the secant method is used to find the optimal solution at each hour. In this section, Secant method is presented to solve the ED problem. The following two steps are involved in the proposed method. The secant method [3, 4] is a root finding algorithm that uses a succession of roots of secant lines to better approximate a root of a function. This method assumes that the function is approximately linear in the local region of interest and uses the zero crossing over the line connecting the limits of the interval as the new reference point. The next iteration starts from evaluating the function at the new reference point and then forms another line. The process is repeated until the root is found. Geometrically, Newton method uses the tangent line and secant method approximates the tangent line by secant line. The secant method has super linear convergence. It will converge within five iterations if the guess value is correct. To find the root of $f(x)=0$ in the interval of $(x 0, x 1)$ with which $f\left(x_{0}\right)$. $f\left(x_{1}\right)<0$.

$$
x_{k+1}=x_{k}-\frac{x_{k}-x_{k-1}}{f\left(x_{k}\right)-f\left(x_{k-1}\right)} f\left(x_{k}\right)
$$

2) The application of Secant method for EDP is as follows, the power balance equation is written as function of lambda. Therefore

$$
f(\lambda)=\sum_{i=1}^{n g} P_{i}(\lambda)-P D_{t}
$$

3) For the secant method, the values of $x_{k-1}, x_{k}, f\left(x_{k-1}\right)$ and $f\left(x_{k}\right)$ are selected as follows: At specified power demand, two rows are selected from the IPPD table such that the power demand lies within the SOP limits and these two rows are formed as a table is known as Reduced IPPD (RIPPD) table-I.

Table-I: Reduced Improved Pre-prepared Power Demand table (RIPPD)

\begin{tabular}{|c|c|c|c|}
\hline S.no & $\lambda$ & $P_{i}(\lambda)$ & $S O P=\sum_{i=1}^{n g} P_{i}$ \\
\hline 1 & $\lambda_{\min }$ & $P_{i}\left(\lambda_{\min }\right)$ & $\mathrm{SOP}_{\min }$ \\
\hline 2 & $\lambda_{\max }$ & $P_{i}\left(\lambda_{\max }\right)$ & $\mathrm{SOP}_{\max }$ \\
\hline
\end{tabular}

$$
\begin{aligned}
& x_{k-1}=\lambda_{\min } \& f\left(x_{k-1}\right)=\sum_{i=1}^{n g} P_{i}\left(\lambda_{\text {min }}\right)-P D_{t} \\
& x_{k}=\lambda_{\max } \& f\left(x_{k}\right)=\sum_{i=1}^{n g} P_{i}\left(\lambda_{\max }\right)-P D_{t}
\end{aligned}
$$

4) If $P_{i}$ violates the generator limits, then set the generating limits as follows:

a) If $P_{i}$ is less than the Minimum limit of generating unit, set $P_{i}$ value is zero.

b) if $P_{i}$ is greater than the maximum limit of generating unit, set $P_{i}$ value is $P_{\max }$

c) if the operating generating unit is must run generator then that unit is always operating in between the minimum and maximum operating range

d) From (7), optimal lambda value is evaluated by secant method at required power demand. The chief advantage of this method is that it converges super linearly to find the root of the polynomial.

\section{Implementation of Algorithm for UCP $[14,2]$}

Step-1 Read the system data Fuel cost data Power demand over 24 hours

Step-2 Formation of IPPD table.

Step-3 Secant method for EDP 


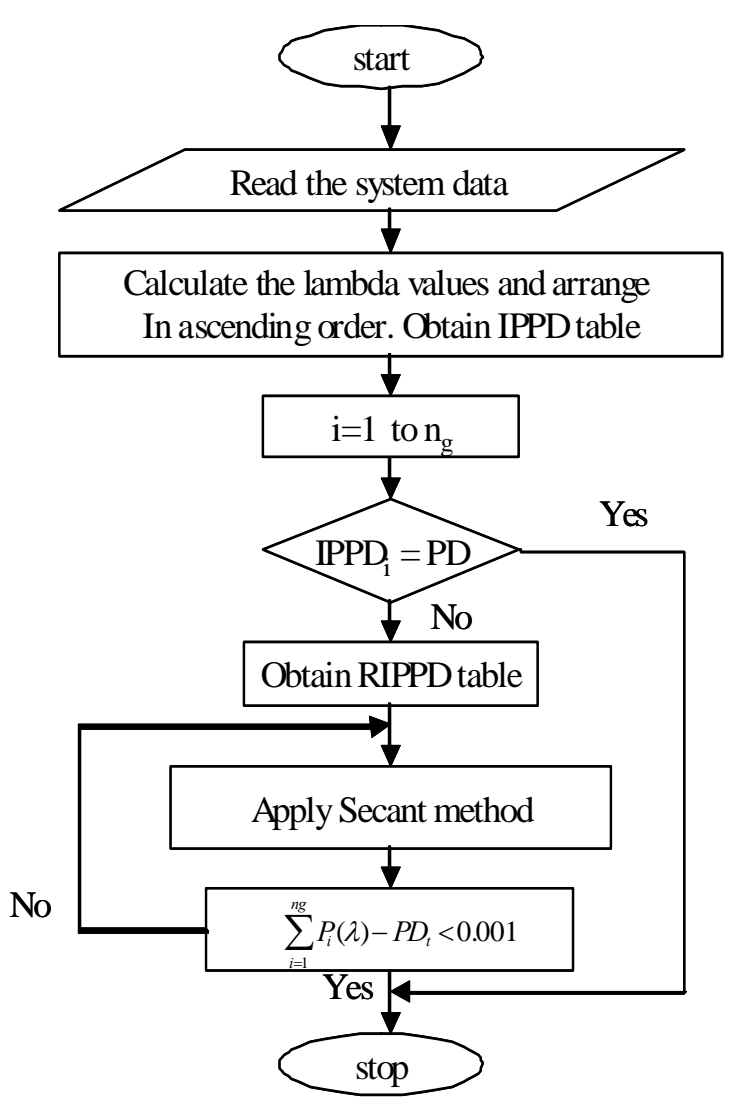

Flow chart of the proposed method

\section{Application and Simulation}

Take a profile continuous fig.(1) daily followed by three gas microturbines [9-12] having the following characteristics: The fuel cost data of three thermal units was given in the table-II.

$P_{1, \max }=28 \mathrm{~kW}, P_{1, \min }=7 \mathrm{~kW}$

$P_{2, \max }=56 \mathrm{~kW}, P_{2, \min }=14 \mathrm{~kW}$

$P_{3, \max }=84 \mathrm{~kW}, P_{3, \min }=14 \mathrm{~kW}$

The fuel cost data [5] of three thermal units was given in the table-II.

TABLE II. - Units fuel cost data

\begin{tabular}{|c|c|c|c|}
\hline Unit & $a_{i}$ & $b_{i}$ & $c_{i}$ \\
\hline 1 & 100 & 6 & 0.005 \\
\hline 2 & 300 & 8 & 0.0025 \\
\hline 3 & 500 & 10 & 0.002 \\
\hline
\end{tabular}

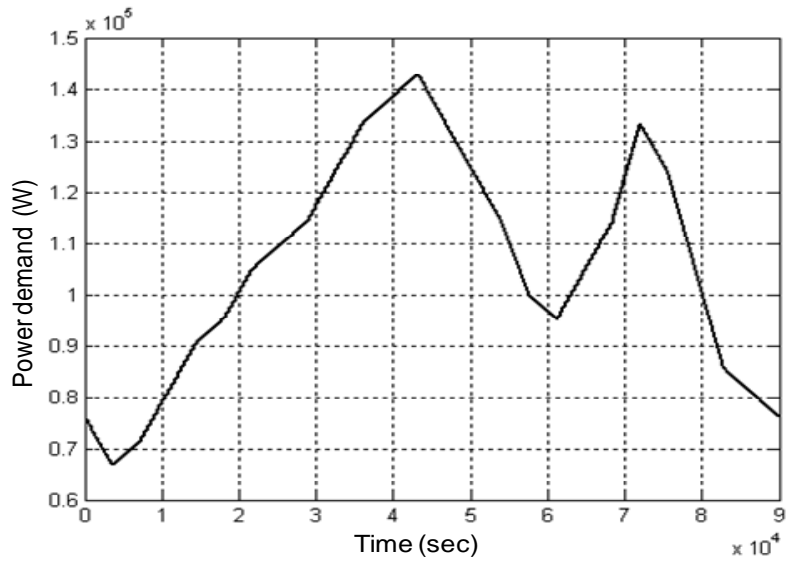

Fig.1. Daily Load profile

A. Assume the classical strategy of the economic dispatch as follows $[9,10]$ :

1) The first microturbine participates in $10 \%$ of the power demand and a cold start i.e. it will have 172 seconds of delay before providing power.

2) The second microturbine participates in $30 \%$ of the power demand and a hot start.

3) The third microturbine participates in $60 \%$ of the power demand and a hot start.

B. Apply the Secant method, as a solution to the unit commitment problem on these three microturbines to determine the microturbine power that each should provide to meet the demand for power used in the first strategy.

In the first time, present the powers provided by the three MTG in fig. (2, a-b) to achieve the objective:

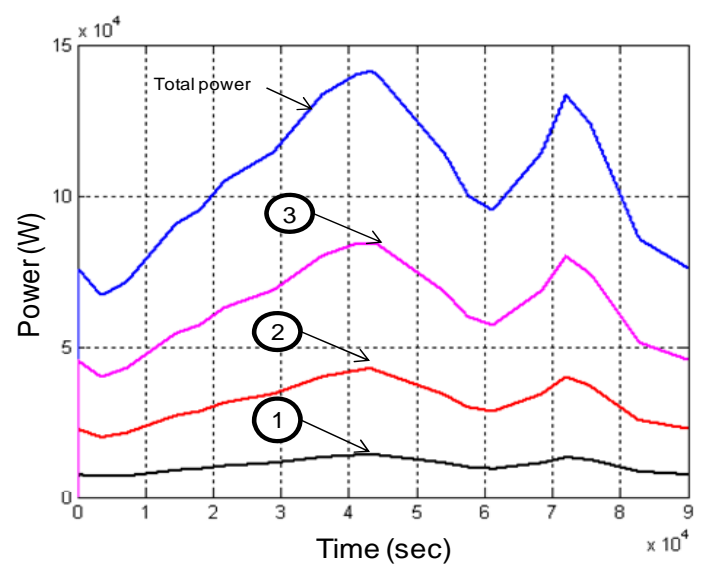

Fig.2, a. Output generated power for three units [Classical method] 


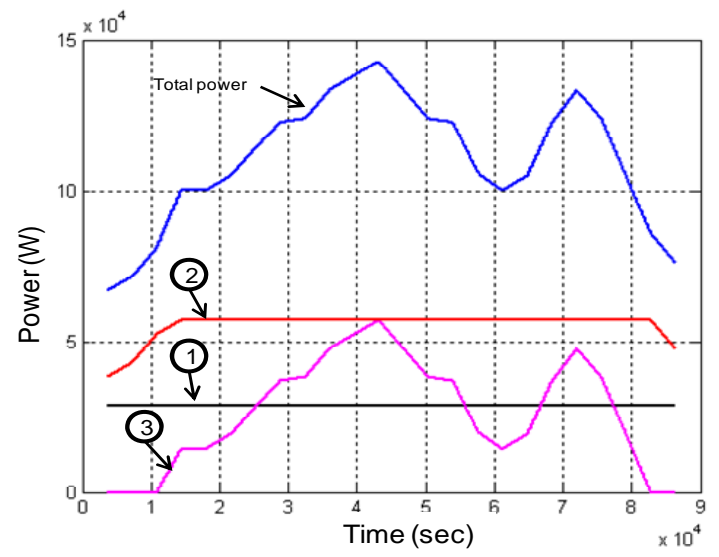

fig.2, b. Output generated power for three units [Secant method]

The principal constraint of the optimization strategies is that the power produced by the three generators must be equal to the power demand. What distinguishes this method is that other strategies in the optimal case on a single generator that is online in some regions of operation. In fig.(2,b), the MTG1 (black) delivers its rated power $(28 \mathrm{~kW})$ throughout the day, while MTG3 (pink) varies its power to ensure that the principal constraint is satisfied. Then, the linearity of the powerconsumption relationship [12] gives us the fig.(3,a-b).

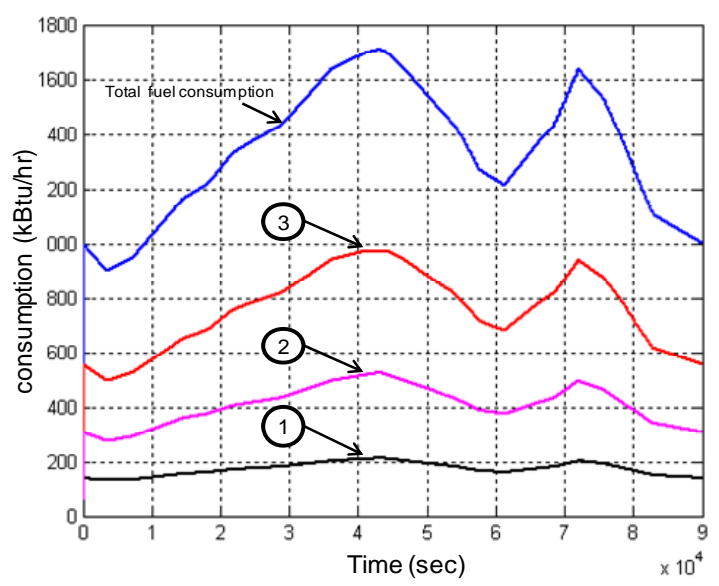

Fig.3, a. Units fuel consumption [Classical method]

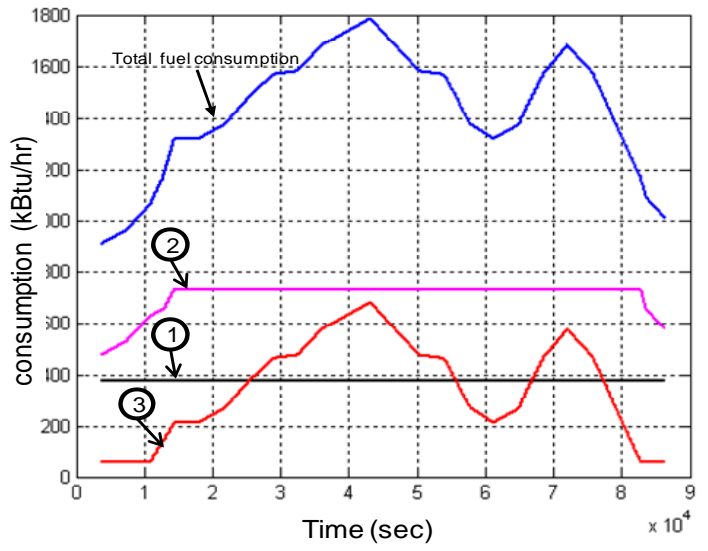

fig.3, b. Units fuel consumption [Secant method]

By integrating the curves of consumption we obtain in fig. $(4, a-b)$ the curves quantity of consumed fuel at the end of the day.

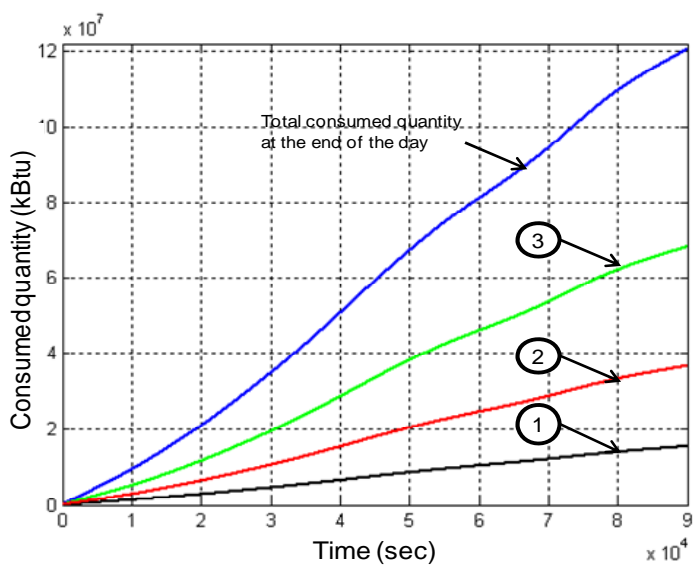

Fig.4, a. Fuel consumed quantity at the end of the day [Classical method]

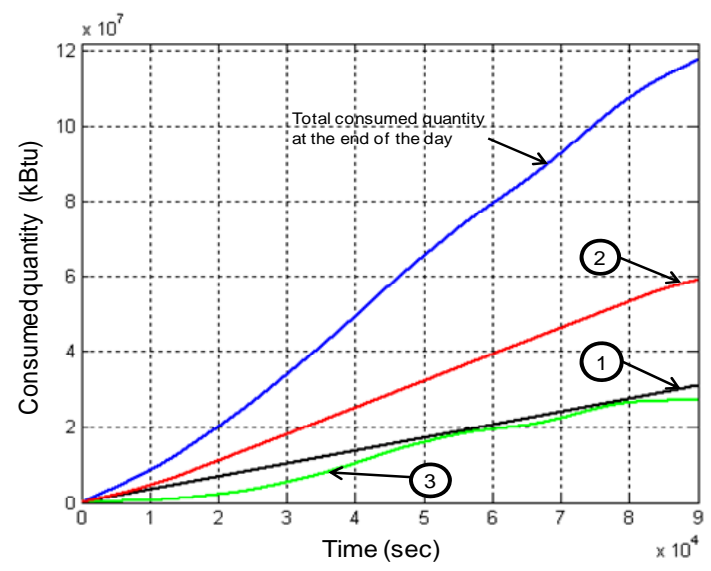

fig.4, b. Fuel consumed quantity at the end of the day [Secant method] 
As show in fig.(4, a-b), the amount of the quantity consumed by the classical strategy is about $12.054 \mathrm{e} 7$ (kBtu), while that by the secant method proposed is about $11.897 \mathrm{e} 7 \mathrm{(kBtu})$, i.e. that the difference is about $0.1570 \mathrm{e} 7$ (kBtu).

Finally, by applying the cost function at any time, we get the cost to the powers provided by the microturbines, for each strategy.

The results for four hours are arranged in Table III.

Table III. - Fuel cost for four hours

\begin{tabular}{|c|c|c|c|}
\hline hour & $\begin{array}{c}\text { Power } \\
\text { demand }(\mathrm{kW})\end{array}$ & $\begin{array}{c}\text { Fuel cost (\$) } \\
\text { by classical } \\
\text { method }\end{array}$ & $\begin{array}{c}\text { Fuel cost (\$) } \\
\text { by proposed } \\
\text { method }\end{array}$ \\
\hline 1 & 66.7 & 1504.5 & 1383.9 \\
\hline 7 & 109.5 & 1897.7 & 1826.2 \\
\hline 12 & 142.8 & 2205.8 & 2118.8 \\
\hline 20 & 133.3 & 2117.7 & 2021.5 \\
\hline \multicolumn{2}{|c|}{ Total cost (\$) } & 7725.7 & 7350.4 \\
\hline
\end{tabular}

\section{Conclusion}

This paper has suggested particle swarm optimization combined with IPPD table for solving unit commitment problem. This work consisted in its entirety in a technoeconomic study whose objective was to minimize fuel consumption of a small central cogeneration multimachine. Initially for all power demands, the unit status is determined by IPPD table then the optimal solution is obtained by secant method. In the final part we had the opportunity to compare simulation example of our strategy of sharing power applied on three different microturbines, in our proposed method to minimize the fuel cost.

\section{References}

[1] K.Chandram, Dr. N.Subrahmanyam, M.Sydulu , National Institute of Technology, Warangal, A.P, INDIA "Dynamic Economic Dispatch by Equal Embedded Algorithm”, 4th International Conference on Electrical and Computer Engineering. ICECE 2006, 19-21 December 2006, Dhaka, Bangladesh.

[2] Chandram, K. Subrahmanyam, N. Sydulu, M.,Dept. of Electr. Eng., Nat. Inst. of Technol., Warangal; "New approach with Secant method for solving Unit Commitment problem” IEEE/PES T\&D. Transmission and Distribution Conference and Exposition, 2008. Volume, Issue , 21-24 April 2008 Page(s):1 - 7.

[3] H.M.Antia "Numerical methods for Scientists and engineers” 2nd ed., 2002 Birkhäuser publishers.
[4] Press, W. H. Flannery, B. P. Teukolsky, S. A.; and Vetterling, W. T. "Secant Method, False Position Method, and Ridders' Method.” 9.2 in Numerical Recipes in FORTRAN: The Art of Scientific Computing, 2nd Ed.

[5] C.P.Chang, C.W.Liu and C.C.Liu,"Unit commitment by Lagrangian relaxation and genetic algorithms", IEEE Trans Power Syst 15 (2000) (2), pp. 707-714.

[6] Carlos A. Hernandez-Aramburo, Member, IEEE, Tim C. Green, Member, IEEE, and Nicolas Mugniot "Fuel Consumption Minimization of a Microgrid", IEEE transactions on industry applications, vol. 41, NO. 3, May/June 2005.

[7] C.C.A. Rajan, M.R. Mohan and K. Manivannan 'Neural-based tabu search method for solving unit commitment problem'’IEE Proceedings-Generation, transmission and Distribution, India, July 2003, pp.469474.

[8] N.P.Padhy, "Unit commitment-a bibliographical survey”, IEEE Trans Power Syst 19 (2004) (2), pp. 11961205.

[9] P. LI, Ph. DEGOBERT, B. ROBYNS, B. FRANCOIS, " Modelling and Control of a Micro Turbine Generator by Using Causal Ordering Graph, Computational Engineering in Systems Applications": CESA, Beijing, China, 4-6 Octobre, 2006, CDROM.

[10] J. Herbreteau, V. Courtecuisse, P. Li, Ph. Degobert, B. Robyns, B. François, Association of PV, gas micro turbine and short term storage system to participate in frequency control, International Conference on Renewable Energy and Power Quality (ICREPQ'08), March 12-14, 2008, Santander, Spain

[11] Ph. Degobert, S. Kreuawan, X. Guillaud, "Micro-grid powered by photovoltaic and micro turbine”, International Conference on Renewable Energy and Power Quality (ICREPQ'06) April 2006, Palma de Mallorca, Spain, CDROM

[12] Capstone Turbine Corporation, 410004 Rev. D (April 2006). Technical Reference.

[13] Thierry BENOIST, BOUYGUES/e-lab, Maurice DIAMANTINI ENSTA/LMA, Benoît ROTTEMBOURG BOUYGUES/e-lab "Relaxation lagrangienne et filtrage par coûts réduits appliqués à la production d'électricité ', rapport ENSTA, 4 juin 2005, 30p.

[14] K.Chandram, N.Subrahmanyam, M.Sydulu. "Equal Embedded Algorithm for Large Scale Economic Load Dispatch”. 1-4244-1298-6/07 (C2007 IEEE. 